\title{
USO DOS PERFIS GEOFÍSICOS EM UM POÇO DA BATERIA DA PRAÇA GONÇALVES LEDO (MACEIÓ), REVESTIDO COM PVC
}

\author{
Geraldo GIRÃO Nery ${ }^{1}$ \\ Perillo ROSTAN de Mendonça Wanderley ${ }^{2}$ \\ Abel Tenório CAVALCANTE ${ }^{3}$
}

\section{RESUMO}

A presença de altíssimas radioatividades em perfis corridos em poços que tenham produzido continuamente durante alguns anos, é fato relatado em várias publicações da indústria do petróleo. Tais anomalias, crostas radioativas aderidas ao revestimento, resultam da liberação dos isótopos do $\mathrm{K}^{40}$, Urânio e Tório, durante interações entre a água porosa e os argilominerais, provocando tamponamento dos intervalos filtrantes, forçando os fluidos interporosos a migrarem através do cimento micro ou macro fraturado, em busca de locais de menores pressões.

O poço objeto deste trabalho, inicialmente produzindo $150 \mathrm{~m}^{3} / \mathrm{h}$ com $65 \mathrm{mg} / \mathrm{l}$ de cloretos, após 75 meses de produção, sofreu um substancial aumento nesse teor da ordem de 18,5 vezes $(1.200 \mathrm{mg} / \mathrm{l})$. Providências tipo redução da vazão para 50 $\mathrm{m}^{3} / \mathrm{h}$ proporcionaram redução no teor de cloretos.

Devido à ocorrência dessa salinização, programou-se uma perfilagem geofísica com os perfis de Indução e Raios Gama, com a finalidade de investigar possíveis rotas de migração fluida.

1 HYDROLOG Serviços de Perfilagens Ltda - Diretor de Marketing - hydrolog@e-net.com.br

2 CONSULTOR em Hidrogeologia - prmw@fapeal.br

${ }^{3}$ CASAL-Companhia de Abastecimento e Saneamento do Estado de Alagoas - Consultor - atc@fapeal.br 


\section{INTRODUÇÃO}

A explotação de águas subterrâneas, de baixo custo e excelente potabilidade, passou a ser a alternativa mais viável para aumentar a oferta de água da cidade de Maceió. Atualmente, do total de $2 \mathrm{~m}^{3} / \mathrm{s}$ para o abastecimento desta capital, mais de $80 \%$ é de origem subterrânea obtida através de cerca de 200 poços tubulares operados pela CASAL - Companhia de Abastecimento d'Água e Saneamento do Estado de Alagoas

Algumas baterias de poços, localizadas nos vales e próximas à planície litorânea, como as do Baixo Reginaldo e a do Bebedouro, provavelmente devido à super explotação, começaram a apresentar um aumento gradativo no teor de cloretos. Mesmo em áreas mais afastadas, alguns poços já produzem águas com altos teores de sais de origem marinha(?) (tabela 1), como os da bateria da Praça Gonçalves Ledo, localizada, aproximadamente a uma distância, em linha reta, de $4 \mathrm{~km}$ do litoral. Essa bateria está no domínio do tabuleiro costeiro, já próximo a falésia que passa pela planície litorânea de Maceió (figura 1).

Os quatro poços da Praça Gonçalves Lêdo receberam as siglas: PGL-01, PGL-02, PGL-03 e PGL-04
(Poços Gonçalves Lêdo) e entraram em operação a partir de 1987, com a construção do poço PGL-01, com uma produção total de $300 \mathrm{~m}^{3} / \mathrm{h}$.

A partir de 1990, o monitoramento das águas detectou o início de um processo de salinização, principalmente no poço PGL-02. Posteriormente, os poços PGL-03 e PGL-01, apresentaram valores crescentes de cloretos. O único poço ainda não afetado pelo processo de salinização foi o PGL-04.

O poço 02 , objeto deste trabalho, inicialmente produzia $150 \mathrm{~m}^{3} / \mathrm{h}$, mas com o aumento da salinidade de sua água, que chegou a alcançar cerca de 1.200 $\mathrm{mg} / \mathrm{l}$ de cloretos, teve sua vazão reduzida para $50 \mathrm{~m}^{3} / \mathrm{h}$, obtendo-se assim uma apreciável redução no teor de cloretos.

A bateria da referida praça continua em operação, com vazões mais reduzidas, misturando-se suas águas com as de poços de outros áreas que não apresentam teores elevados de sais.

\section{HIDROGEOLOGIA}

Os poços da Praça Gonçalves Ledo estão localizados na Bacia de Alagoas, penetraram totalmente a Formação Barreiras e, parcialmente, a Formação Marituba, aqüíferos explotados localmente. 
Os parâmetros hidrodinâmicos de ambos os sistemas são bastante variáveis.

CAVALCANTE

(1996), estimou para o Barreiras/Marituba uma transmissividade entre $3,840.10^{-4}$ e $1,900.10^{-2} \mathrm{~m}^{2} / \mathrm{s}$, enquanto para 0 Barreiras, este coeficiente apresentou valores entre $1,610.10^{-4}$ e $1,350.10^{-2} \mathrm{~m}^{2}$ /s.

\section{PERFILAGEM GEOFÍSICA}

Todos os poços da referida bateria não foram perfilados logo após a perfuração (perfilagem em poço aberto). Todavia, devido à ocorrência de salinização, programou-se uma perfilagem geofísica composta dos perfis de Indução e Raios Gama, com a finalidade de investigar, no PGL-02, possíveis rotas de migração fluida.

$\mathrm{Na}$ indústria de petróleo é comum a constatação de altíssimas radioatividades em perfis corridos em poços que tenham produzido continuamente durante alguns anos. Essas anomalias pós-produção ocorrem, costumeiramente, na forma de crostas radioativas por trás do revestimento, como resultado da liberação dos isótopos do $\mathrm{K}^{40}$, Urânio e Tório, solubilizados durante as interações entre a água porosa e os minerais, principalmente os argilominerais. Com o passar do tempo ocorre um tamponamento

dos intervalos canhoneiados (equivalentes aos intervalos filtrantes da água), forçando os fluidos interporosos a migrarem por trás do revestimento, através do cimento micro ou macro fraturado, em busca de locais com menores pressões. É conveniente lembrar que o pré-filtro usado na água para preencher o anular é, na realidade, um corpo permoporoso. Como o PGL-02 estava revestido com filtros e tubos de PVC, nada impediria um uso satisfatório das curvas de Indução e Raios Gama. As ondas eletromagnéticas do Indução penetrariam normalmente nas camadas, servindo para o estudo das variações das resistividades das rochas e/ou fluidos interporosos, enquanto que o RG poderia fornecer informações litológicas, além de auxiliar na detecção das anomalias radioativas, sugestivas de possíveis migrações fluidas. Existiam dúvidas quanto as curvas elétricas, Normal Curta (SN) ou SP, por necessitarem de contato galvânico para seus eletrodos registrarem 0 desenvolvimento das correntes elétricas. O presente trabalho, pioneiro na indústria da água, é um estudo de caso dos perfis de Indução e Raios Gama, corridos no poço tubular PGL-02, localizado na Praça Gonçalves Ledo, Maceió, com profundidade final perfilada de 145,8 metros e filtros de PVC 
posicionados, de acordo com o projeto, aos 77-89, 93-131 e 139-149 metros.

4. DADOS DA PERFILAGEM (Figura 2)

\section{1 - Curva dos Raios Gama}

\section{Convencional (RG)}

Os intervalos 72-74, 83-107 e 125-127 metros, apresentam altíssimos valores de radioatividade (GAPI). O intervalo 83$107 \mathrm{~m}$, localizado entre a porção mais inferior do primeiro intervalo filtrante com a porção mais superior do segundo, tem sua alta radioatividade creditada à ocorrência de incrustações no pré-filtro, filtros e tubos cegos, como resultado de uma movimentação fluida intensa, interligando os intervalos filtrantes superior e inferior. Uma baixa radioatividade ocorre nos demais intervalos, sem muita conotação hidrodinâmica. O restante da curva apresenta-se dentro da normalidade.

As análises hidrodinâmicas (tabela 1) realizadas desde novembro de 1993 até fevereiro de 2000, mostram um aumento substancial na concentração dos principais íons presentes na água do mar $\left(\mathrm{Cl}^{-}, \mathrm{Na}^{++}, \mathrm{SO}_{4}=\mathrm{Mg}^{++}, \mathrm{Ca}^{++}\right)$, exceção do potássio, não observado nas quatro análises anteriores, por ausência ou por não solicitação, pelo usuário, de sua quantificação.
4.2 - Curva de Indução Profunda 6FF40 (Deep Induction Resistivity - DIR)

Devido ao fato de o poço estar localizado em uma praça, com redes elétricas e tubulações metálicas subterrâneas ou aéreas, nota-se um aspecto altamente errático da DIR até os 59 metros, quando ela inicia a registrar valores compatíveis com rochas e não com efeitos superficiais e/ou telúricos, exceto na presença de artefatos metálicos, discutidos a seguir.

Corpos metálicos, circundando as bobinas transmissoras e receptoras do equipamento, mostram um comportamento típico de "zig-zag" característico da curva do Indução. Tais comportamentos (valores repentinos de altos e baixos na DIR), que podem ser observados, nitidamente, entre 53-59, 71-77, 84-89, 108-113, 135-137 e 144146 metros, correspondem a centralizadores metálicos da coluna de completação. Acima de 53 metros, não há diagnóstico certo, estimando-se os centralizadores em torno dos 40, 32 e 25 metros.

O comportamento da DIR, abaixo dos $85 \mathrm{~m}$, mostra uma diminuição crescente da ordem de 30-40 Ohm.m para 3-4 Ohm.m aos $135 \mathrm{~m}$, indicando a presença de rochas com águas interporosas aumentando de salinidade com a profundidade. 
4.3 - Curva Normal Curta 16" na diferença de resistividades (Short Normal - SN) (salinidades) entre os fluidos do poço e das camadas permoporosas. Observa-

Esperava-se que a $\mathrm{SN}$ não se na curva do $\mathrm{SP}$, que acima dos funcionasse a contento, devido a primeiros filtros, por inexistência de possível ausência de acoplamento contato físico entre fluidos, a curva galvânico para a difusão da corrente mostra-se errática, exceto a partir de elétrica utilizada. $O$ fato de se ter topo da primeira seção filtrante até o saturação da SN (altos valores em linha fundo perfilado, quando permanece reta, reta) dos $10 \mathrm{~m}$ até o topo dos primeiros e aos 131-136m quando registra -125 filtros, confirma este raciocínio. Com $\mathrm{mV}$.

base neste fato, observa-se um tubo cego entre $87-90 m$ e que o intervalo 131-139 m, projetado para ser de tubo cego, foi posicionado, na realidade entre 128-136m, de acordo com o comportamento da Normal Curta.

Abaixo de 77 metros, a SN tornase bastante similar à DIR, sendo maior que esta entre 77-90m, menor entre 90$105 \mathrm{~m}$ e aproximadamente igual à DIR dos $105 \mathrm{~m}$ até o fundo do poço.

Por se tratar de um longo intervalo filtrante, o acoplamento elétrico fdeve ter sido realizado através das aberturas dos filtros, possibilitando a SN ter comportamento esperado e coerente com a DIR, exceto nos intervalos dos tubos cegos, citados acima.

4.4 - Curva do Potencial Espontâneo (SP)

A curva do SP funciona com base na mobilidade (permeabilidade) iônica e

\section{c} partir dos primeiros filtros, aos 77
Como o poço fôra desativado para a perfilagem, inexistia lama e sim o próprio fluido produzido funcionando como o fluido invasor. Assim, a curva, teoricamente, não deveria funcionar por inexistência de contraste fluido. Entretanto como justificar os $-125 \mathrm{mV}$ defronte o intervalo 131-136 metros? A explicação lógica é a de que tenha ocorrido movimentação fluida no local, originando um potencial eletrocinético que negaria a presença do tubo cego, conforme o projeto do poço, ou então este tubo estaria bastante corroído e perfurado, permitindo assim o contato fluido.

\section{INTERPRETAÇÃO DOS PERFIS}

As curvas DIR e SP, na parte mais rasa do poço, mostram um intenso comportamento errático que pode ser creditado à alta energização da praça. A 
metros, exceto pelas anomalias já discutidas, as curvas dos perfis funcionaram a contento, podendo ser interpretadas em termos de rocha e/ou artefatos (centralizadores metálicos).

Para que fosse possível a realização de uma boa interpretação qualitativa e quantitativa, a primeira preocupação dos autores foi à reconstituição do perfil através de uma interpolação numérica, não linear, seguindo à tendência mais realista para cada curva (DIR, SP e RG) e a eliminação daqueles locais de interferência dos centralizadores metálicos e incrustações. Esta providência auxiliou na identificação dos corpos argilosos dos não argilosos. $\mathrm{O}$ resultado é mostrado na figura 3 .

Lamentavelmente, o PGL-02 não foi perfilado geofisicamente quando em aberto. Esta foi à razão pela qual sua coluna filtrante foi posicionada com base nas amostras de calha, sabidamente passíveis de indicações falhas de profundidade e litologia, devido a desmoronamentos e incorporações de fragmentos outros que não aqueles triturados pela broca, no momento da profundidade referida pelo sondador.

\section{1 - Interpretação Qualitativa:}

Nota-se na figura 3 que os locais mais indicados para os filtros deveriam ter sido entre 88-102 e 107-116 metros.
As curva SN e DIR, por princípio, separam-se numericamente por diferença de resistividade entre as zonas lavada e a virgem, em se considerando invasões médias (diâmetros da ordem de 40"). Assim, separações visuais e numéricas entre ambas as curvas sugerem permoporosidade, conforme se poderá observar entre 88-102 e 107$116 \mathrm{~m}$. No caso, sendo a DIR > SN, pode-se admitir a ocorrência de um fluido virgem mais doce que o invasor, longe do alcance da investigação da SN. Admite-se, que os intervalos acima mencionados ainda não estejam invadidos pela cunha salina. Espera-se que o folhelho entre 102-107m (ver SN $\approx$ DIR) possa atuar como uma barreira de permeabilidade para a invasão salina que se processa, atualmente, a partir do fundo até aproximadamente $122 \mathrm{~m}$, pelas razões apontadas a seguir.

Quando as curvas SN e DIR estão lendo valores aproximados, como o abaixo dos 122m, admite-se uma igualdade nas salinidades dos fluidos invasor e virgem. Nesse caso, o PGL-02 deve estar produzindo água virgem, que gradativamente se torna mais salgada com a profundidade, dado o gradiente que pode ser observado em ambas as curvas.

Estando a secção superior $\mathrm{e}$ intermediária incrustada (ver o RG), a produção poderia estar vindo dos filtros 
inferiores, onde a água intersticial é bem mais salgada, admitindo-se uma possível invasão marinha atual, passando por trás do revestimento, incrustando sais e se misturando com a água dos filtros superiores mais diluídas.

Esta hipótese esta baseada nas figuras 3 (reconstituição) e 4 (inversão) que mostram a variação numérica das resistividades com o tempo.

\section{2- Interpretação Quantitativa:}

\subsection{1 - Relação Teor de Sais} Dissolvidos Totais $(S D T)$ e $\quad$ a Resistividade da Água (Rw) : Para a obtenção da equação hiperbólica da área, capaz de relacionar SDT com Rw (Girão Nery, 1996), usou-se as análises hidrodinâmicas realizadas desde a instalação do poço, em 11/93, até 02/00 (tabela 1).

Observa-se um incremento na Condutividade Elétrica medida em Laboratório - C.E.(Lab) - e do teor de SDT, exceto em 12/95. Nesta data, constata-se uma incoerente diminuição da C.E. (Lab) correspondendo a um aumento no SDT. Cálculos obedecendo a tendência da correlação entre ambos os valores apontam como sendo 504 $\mu \mathrm{S} / \mathrm{m}$ o mais provável para a condutividade e não os $213 \mu \mathrm{S} / \mathrm{m}$ indicados.
Apesar de esta possível incorreção, a equação determinada apresentou um coeficiente de correlação de $80 \%$, tendo sido usada nos cálculos aqui apresentados, com boa chance de realidade, podendo ser extrapolada para os demais poços da área (figura 5) :

$$
\mathrm{SDT}=\frac{4311}{\mathrm{Rw}} \mathrm{w}^{0,695}
$$

\subsection{2 - Cálculos Quantitativos} (tabela 2) : Para a determinação da resistividade da água intersticial a partir do SP (RwSP), usou-se a metodologia de Lima e Girão (1999), ponderando-a com o Rwa.

Apesar de não se ter um perfil de porosidade estimou-se uma porosidade total de acordo com correlação com poços vizinhos da ordem de $28 \%$. Usando-se a equação de Raymer et al (1980), adaptada para área, e uma matriz de $56 \mu$ s/pé, reconstituiu-se o provável tempo de trânsito $(\Delta t \approx 110$ $\mu s / p e ́$, não se levando, contudo, em consideração, possíveis e eventuais variações nas porosidades.

A Tabela 2, mostra os resultados quantitativos em termos de valores máximos, mínimos e médios, para cada intervalo filtrante. Mostra ainda, que o poço, nas condições atuais, apresenta, no intervalo filtrante superior $(77-87 \mathrm{~m})$, um SDT da ordem de 1.200 ppm; no intervalo filtrante intermediário (90- 
$128 \mathrm{~m})$, cerca de $2.600 \mathrm{ppm}$ e no inferior (136-141,5m), aproximadamente 6.000 ppm. A resistividade da água $(R w)$, calculada para todo o poço, é da ordem de 5,2 Ohm.m @ 32.C e corresponde aproximadamente 2.500 ppm de Sais Dissolvidos Totais, sendo, portanto, cerca de 1,7 vezes mais salgada que a última água produzida pelo poço (análise de 24/02/00, $\mathrm{Rw}=5,5 \quad$ Ohm.m, SDT=1.484 ppm, tabela 1). Este valor de resisitividade, segundo os gráficos da Schlumberger corresponderia a um teor de 1.000 ppm de cloretos.

Comparando-se os valores para todo o poço (tabela 2) com a tabela 1 , verifica-se que os dados dos perfis são bastante compatíveis com os do laboratório, indicando que 0 procedimento e equações usadas são realistas para os dados registrados.

Admitindo-se a hipótese que a base dos filtros superiores e o topo dos intermediários estejam parcialmente colmatados pelas incrustações radioativas, depositadas devido à intensa movimentação ocorrida durante os sete anos de produção, então, os filtros inferiores (salinizados devido ao avanço da cunha salina) sejam os atuais maiores produtores, aumentando consideravelmente a salinidade da água produzida, originalmente com SDT na ordem de $232 \mathrm{mg} / \mathrm{l}$.

\subsection{3 - Reconstituição da DIR à} época da Perfuração (figura 4): Partindose do pressuposto que as condições petrofísicas, à época da perfuração, seriam exatamente as mesmas atuais, pode-se estimar (inverter), com base na equação de Archie, as resistividades originais das rochas e os valores de SDT, desconsiderando-se, porém, a influência da argilosidade e das porosidades sobre as resistividades.

Com os valores invertidos de resistividade profunda, calcula-se um valor médio para o STD da ordem de 650 ppm, correspondendo a um teor de cloretos de 185 ppm. O valor dos cloretos estimados com esta inversão está cerca de 3 vezes maior que o determinado pelo laboratório na ocasião, estando porém resguardada a relação de 3,5:1 encontrada na análise de 11/93 entre os dois íons. O alto valor pode ser resultado da falta de uma curva de porosidade, lembrando que se estimou um valor constante para todo o poço, da ordem de $28 \%$ (item 5.2.2).

\section{CONCLUSÕES :}

1. A bibliografia, até o presente, somente mostra exemplos de revestimentos metálicos com incrustações radioativas. Este é o primeiro trabalho sobre 
incrustações em revestimentos de PVC, no país, quiçá no mundo.

2. Apesar de o aspecto incomum apresentado pelas curvas do perfil RG/IEL, foi possível se estabelecer uma razoável interpretação do mesmo, com base no conhecimento litológico da área.

3. O uso do IEL/GR em poços revestidos com PVC, como no presente caso, é um artifício válido para a interpretação continuada do poço, principalmente em áreas potenciais de risco de avanço de cunha salina. $O$ ideal seria a comparação entre os perfis realizados em poço aberto com os perfis corridos em poço revestido, como é procedimento normal do petróleo. Na sua impossibilidade, este estudo mostra a validade do uso de perfis indutivos e raios gama em poço revestido.

4. A curva da resistividade profunda (DIR) indica a variação da resistividade ou salinidade da zona virgem com o tempo, enquanto a resistividade rasa (SN) indica a variação da resistividade ou salinidade da zona invadida. Por sua vez, o RG indica o caminho preferencial da movimentação aquosa, pelo incremento da radioatividade proporcionado pela deposição dos sais de $\mathrm{U}$, Th e $\mathrm{K}^{40}$.

5. No perfil reconstituído, os intervalos 88-103 e 107-115m, apresentam, de acordo com o confronto de resistividades (DIR > $\mathrm{SN})$, os melhores intervalos produtores, merecendo filtros até aquela última profundidade. Tivesse sido o poço perfilado em aberto e se colocado apenas $23 \mathrm{~m}$ de filtros (figuras 3 e 4 - acima de 115 metros), poder-se-ia ter eliminado a chance de ser ter águas mais salinas dos intervalos inferiores. Lamentavelmente a ausência da perfilagem na ocasião fez com que a completação tivesse sido planejada somente com o auxílio das amostras de calha, resultando na cobertura com filtros de intervalos com altas salinidades.

6. O RG não pode corroborar na separação entre os folhelhos dos não folhelhos, devido às altas radioatividades apresentadas no intervalo. Entretanto, tais radioatividades indicam a presença de crostas depositadas a partir da movimentação fluida entre o filtro médio e superior.

7. Abaixo de 77 metros, onde foram colocadas as primeiras seções 
filtrantes, o comportamento da DIR é de decréscimo com a profundidade, iniciada com 30-40 $\Omega . m$ e terminando com valor quase 10 vezes menor, indicando que, no estado atual do poço, as águas estão bem mais salinizadas a proporção em que se aproxima o fundo do poço, devido ao avanço da cunha salina, que ainda não atingiu as camadas acima de $115 \mathrm{~m}$.

8. A DIR serve também para identificar 0 posicionamento dos centralizadores. Dentro dos intervalos filtrantes, podemos assegurar que centralizadores metálicos foram posicionados entre 53-59, 71-77, 84-89, 108-113, 135-137 e 144-146 metros, todavia, acima dos $53 \mathrm{~m}$, estima-se em torno dos 40, 32 e $25 \mathrm{~m}$, devido a interferências da saturação da SN.
9. Algumas tentativas que se deseje fazer para recuperar este poço, deverão constar de uma filmagem (telediagnóstico), desobstrução dos filtros no máximo até os $100 \mathrm{~m}$ e cimentação até a profundidade final.

10. Estima-se que o avanço da cunha salina esteja se processando a partir do fundo do poço e esperase que sua progressão venha a encontrar alguma dificuldade na possível barreira argilosa acima dos $107 \mathrm{~m}$, lamentavelmente de apenas $4 \mathrm{~m}$.

\section{AGRADECIMENTOS}

Os autores agradecem a CASAL pela autorização de uso das informações aqui contidas e a HYDROLOG pelo apoio logístico ao presente trabalho.

\section{BIBLIOGRAFIA}

CAVALCANTE, A.T. e WANDERLEY P. R. de M. - 1982. Recursos hídricos na área do Campus A. C. Simões - UFAL, Tabuleiro do Martins, Maceió - AL. Revista Scientia as Sapientiam - UFAL, ano V , N ${ }^{\circ}$ 10, dezembro, Maceió-Al p. 22-28.

CAVALCANTE, A. T. - 1996. Recursos hídricos subterrâneos da área de Maceió - AL. Revista Águas Subterrâneas - n 15 . Dez. 96. - São Paulo, p. 108109.

DE LIMA, O.A.L. e GIRÃO NERY. G. - 1999. Determinação da Resistividade Elétrica de Águas intersticiais usando Perfilagens de Potencial Espontâneo. Paper SBGf 149, Anais do Sixth International Congress of the Brazilian Geophysical Society. 
GIRÃO NERY, G. - 1996. Equações Hiperbólicas Relacionando Rw Com SDT. Determinação da qualidade da água através dos Perfis Geofísicos. Anais do 10응 Congresso Brasileiro de Águas Subterrâneas, Salvador, 1996.

RAYMER, L.L., HUNT, E.R., e GARDENER, J.S. - 1980. An Improved Sonic Transit Time-to-Porosity Transform. Trans. SPWLA, Annual Logging Symposium, Paper $P$.
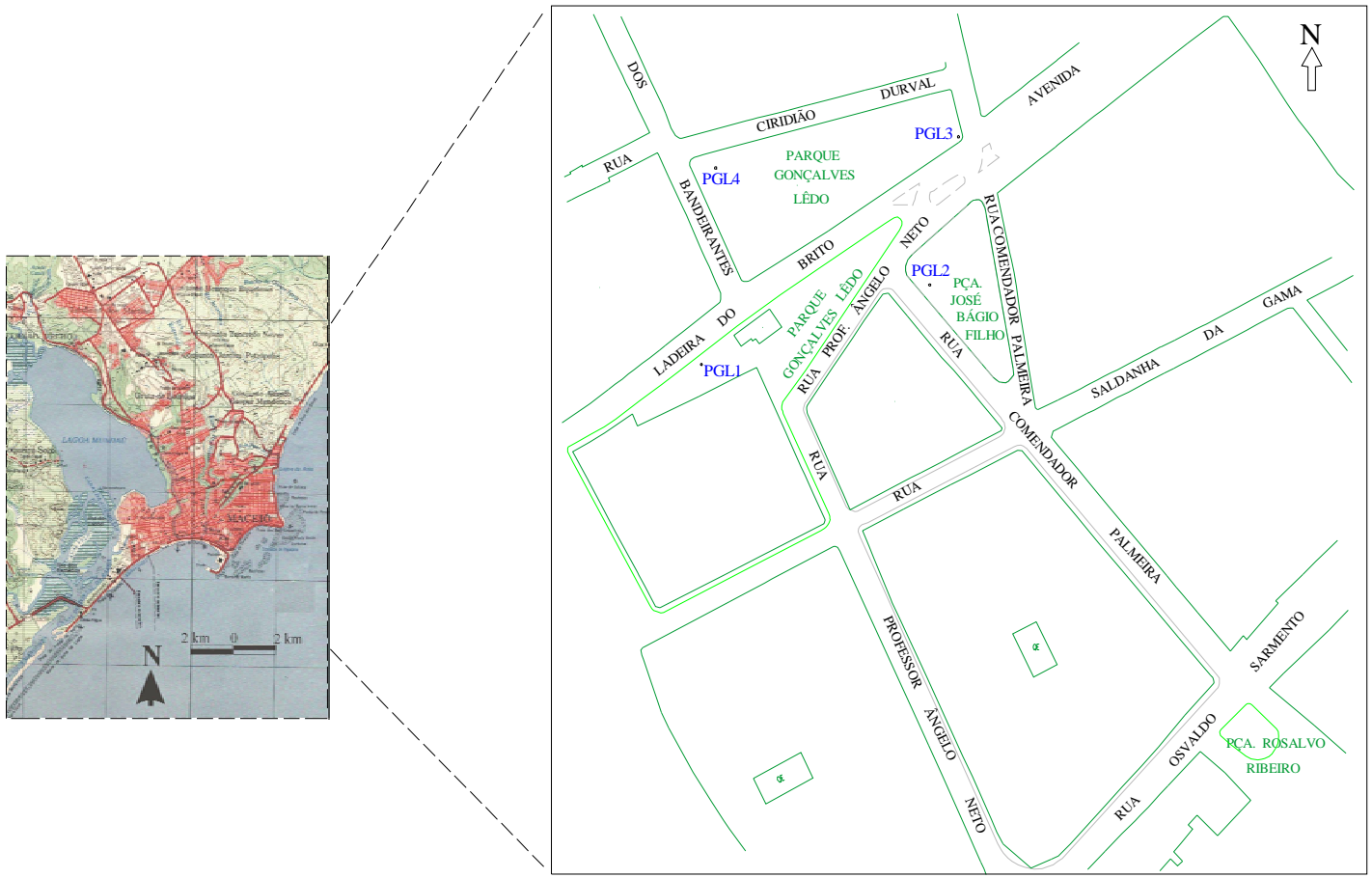

Figura 1 - MAPA DE LOCALIZAÇÃO DA ÁREA DO PARQUE GONÇALVES LÊDO MACEIÓ / AL 




Figura 2 - Perfil IEL/GR originalmente corrido no PGL-02. Curvas tipo "zig-zag" na DIR indicam a presença de corpos metálicos (centralizadores). Altíssimas radioatividades no RG (acima de 500 GAPI) indicam intervalos incrustados. 


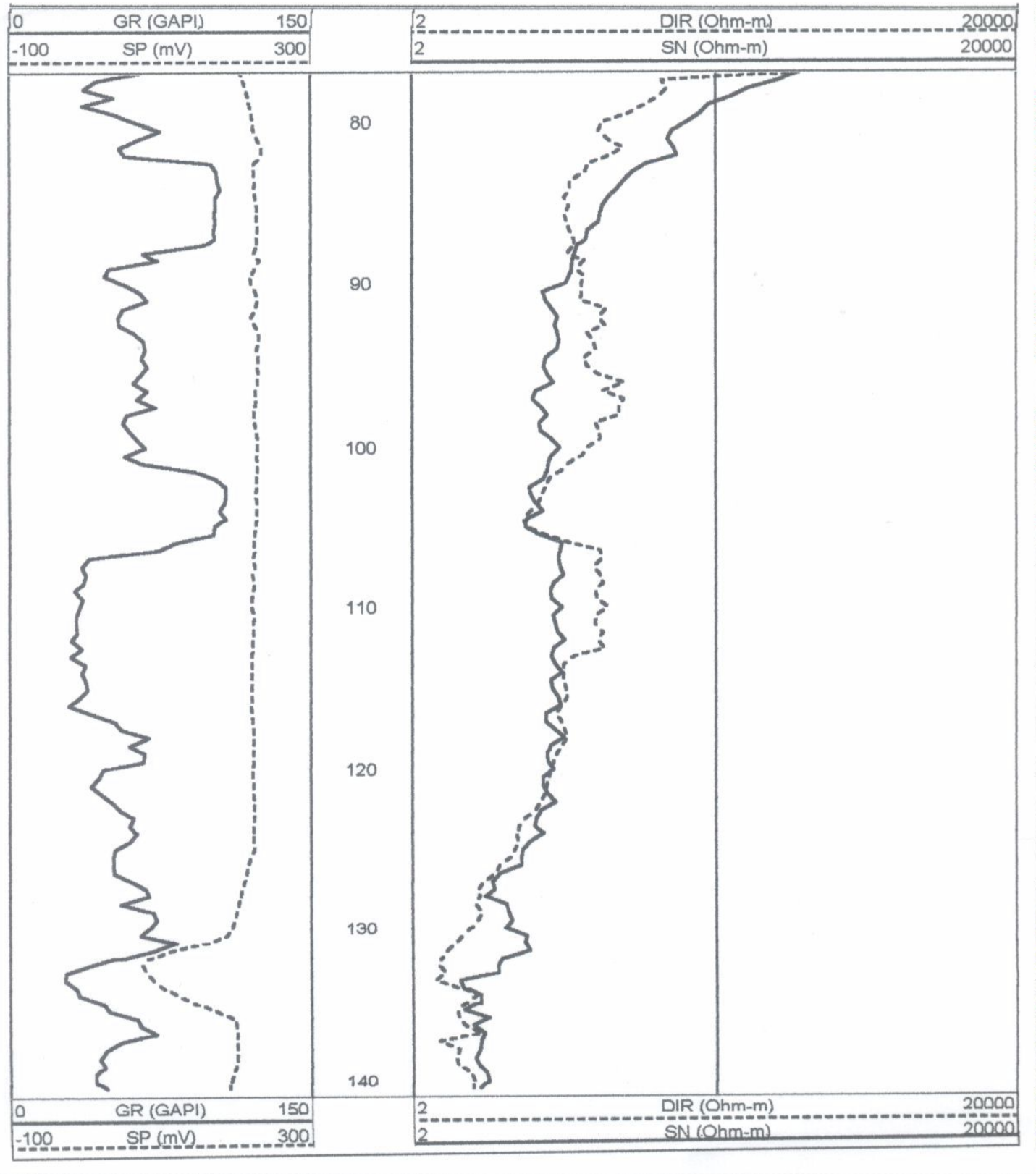

Figura 3 - Perfil reconstituído do PGL-02, mostrando a situação atual do poço caso tivesse sido perfilado sem a influência dos centralizadores, filtros e incrustações. 


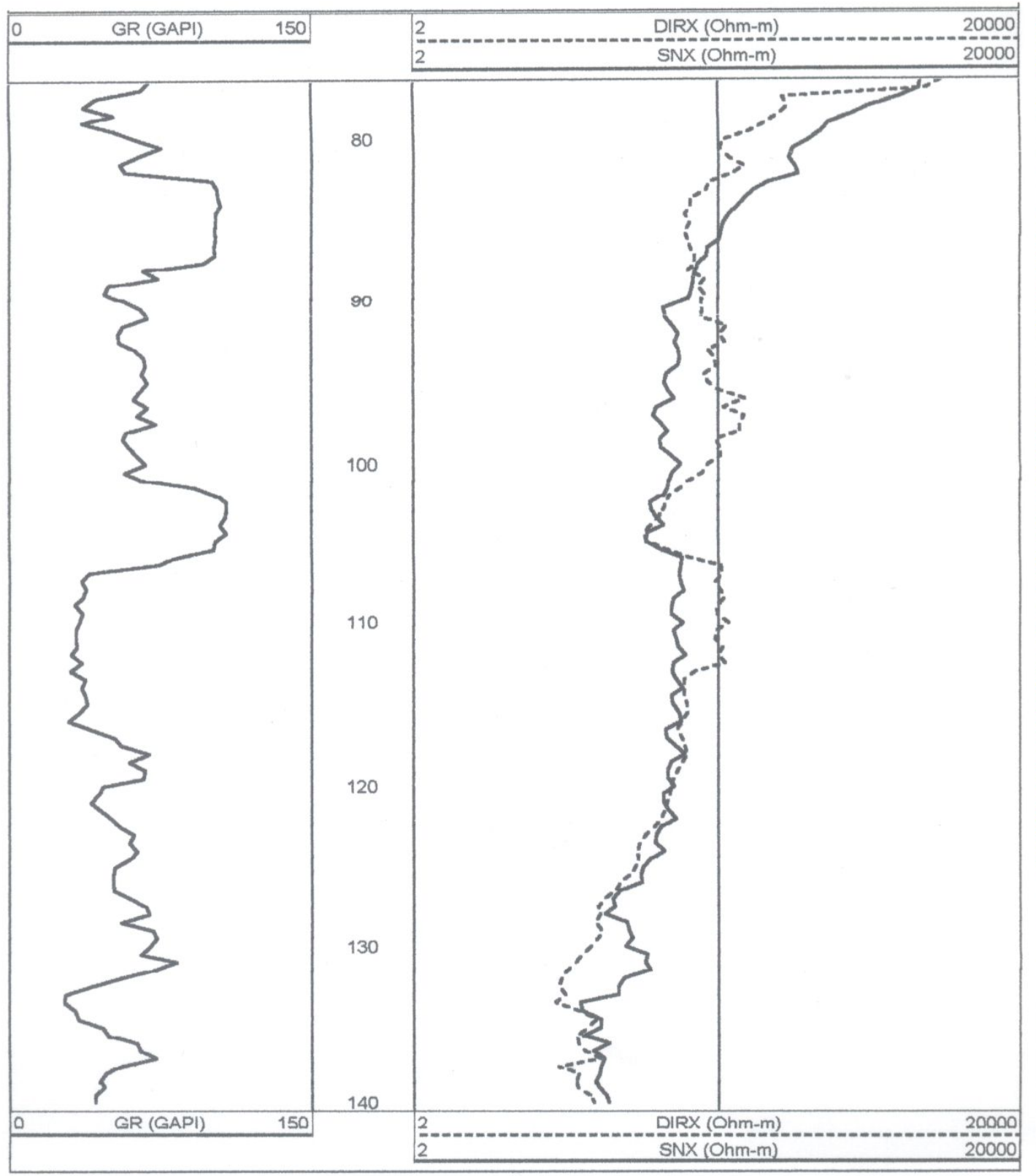

Figura 4 - Curvas DIR e SN invertidas com base na equação de Archie usando a porosidade total dos poços da área. 


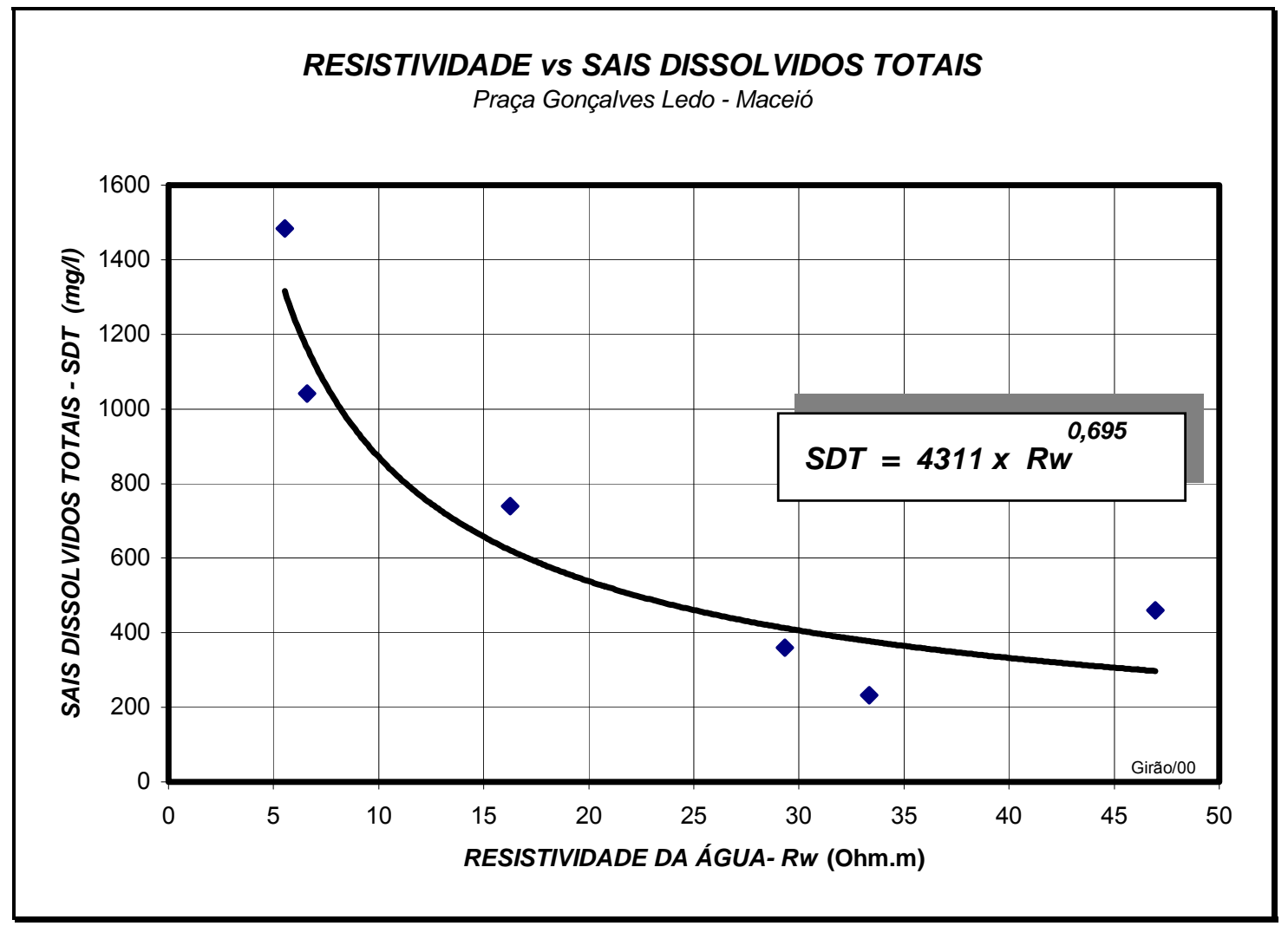

Figura 5 - Definição da relação hiperbólica entre SDT e Rw para o poço PGL-02. 
Tabela 1 - Análises Hidroquímicas do PGL-02. Variação da concentração iônica com o tempo.

\begin{tabular}{|c|c|c|c|c|c|c|c|c|c|c|c|c|}
\hline \multicolumn{2}{|c|}{$L$} & \multirow[b]{2}{*}{$w$} & \multirow[b]{2}{*}{$a$} & \multirow[b]{2}{*}{$g$} & \multirow[b]{2}{*}{$a$} & & \multirow[b]{2}{*}{$I$} & \multirow[b]{2}{*}{$\mathrm{O}_{4}$} & \multirow[b]{2}{*}{$\mathrm{CO}_{3}$} & \multirow[b]{2}{*}{$\mathrm{O}_{3}$} & \multirow[b]{2}{*}{$\mathrm{O}_{3}$} & \multirow[b]{2}{*}{$D T$} \\
\hline ATA & .E. & & & & & & & & & & & \\
\hline & & & & & & & & & & & & \\
\hline $1 / 93$ & 00 & 3,3 & 8 & 0 & & & 5 & 0 & 4 & 4 & & 32 \\
\hline & & & & & & & & & & & & \\
\hline $4 / 95$ & 41 & 9,3 & 8 & 8 & & & 12 & 1 & 4 & 4 & & 60 \\
\hline & & & & & & & & & & & & \\
\hline $2 / 95$ & 13 & 6,9 & 8 & 6 & & & 53 & 0 & 8 & 8 & ,8 & 60 \\
\hline & & & & & & & & & & & & \\
\hline $8 / 96$ & 15 & 6,2 & 6 & 60 & & & 00 & 5 & 0 & 0 & ,9 & 40 \\
\hline & & & & & & & & & & & & \\
\hline $1 / 00$ & 514 & ,6 & 0 & 10 & 80 & 3 & 120 & 0 & 2 & 2 & ,75 & 042 \\
\hline & & & & & & & & & & & & \\
\hline $2 / 00$ & 810 & ,5 & 62 & 48 & 90 & 7,5 & 200 & 07,5 & 6 & 6 & & 484 \\
\hline
\end{tabular}

OBSERVACÕES : C.E. $=$ Condutividade do Laboratório em $\mu \mathrm{S} / \mathrm{cm}$ a $25^{\circ} \mathrm{C}$.

Concentrações em $\mathrm{mg} / \mathrm{l} \approx \mathrm{ppm}$ (dentro da amplitude mostrada)

Rw em Ohm.m a $25^{\circ} \mathrm{C}$

SDT fornecido pelo Laboratório 
Tabela 2 - Resultados atuais por intervalo filtrante e para todo o poço, obtidos a partir dos perfis da HYDROLOG, corridos em 26/06/2000.

Intervalo 77 - 87 metros

\begin{tabular}{|c|c|c|c|c|c|c|c|c|}
\hline - & $D$ & $R$ & $S$ & $D$ & $v$ & $P$ & $R$ & $S$ \\
\hline & IR & $\mathbf{G}$ & $P$ & $T$ & $S H$ & Hle & $w$ & $D T$ \\
\hline$M$ & 1 & 1 & 2 & 1 & 3 & 2 & 1 & 1 \\
\hline ÁXIMO & 00 & 376 & 36 & 10 & 0 & 9 & 5,9 & 485 \\
\hline & 8 & 3 & 2 & 1 & 1 & 2 & 4 & 6 \\
\hline ÍNIMO & & 7 & 05 & 10 & 0 & 3 & ,6 & 30 \\
\hline$M$ & 3 & 4 & 2 & 1 & 2 & 2 & 7 & 1 \\
\hline ÉDIA & 9 & 29 & 25 & 10 & 0 & 4 & 0 & 217 \\
\hline
\end{tabular}

Intervalo 90 - 128 metros

\begin{tabular}{|c|c|c|c|c|c|c|c|c|}
\hline- & $D$ & $F$ & $S$ & $\bar{D}$ & $\bar{V}$ & $P$ & $R$ & $S$ \\
\hline & IR & $\mathbf{G}$ & $P$ & $T$ & SH & Hle & $w$ & $D T$ \\
\hline$M$ & 5 & 9 & 2 & 1 & 2 & 3 & 6 & 6 \\
\hline ÁXIMO & 0 & 13 & 33 & 10 & 5 & 1 & ,2 & 893 \\
\hline$M$ & 4 & 3 & 1 & 1 & 0 & 2 & 2 & 1 \\
\hline ÍNIMO & & 0 & 90 & 10 & & 3 &, 1 & 208 \\
\hline$M$ & 2 & 1 & 2 & 1 & 1 & 2 & 4 & 2 \\
\hline ÉDIA & 2 & 99 & 24 & 10 & 9 & 5 & ,8 & 635 \\
\hline
\end{tabular}

Intervalo 136 - 141,5 metros

\begin{tabular}{|c|c|c|c|c|c|c|c|c|}
\hline- & $D$ & I & $S$ & $D$ & $V$ & $P$ & $R$ & $S$ \\
\hline & IR & $G$ & $P$ & $T$ & SH & Hle & $w$ & $D T$ \\
\hline & 5 & 2 & 2 & 1 & 1 & 2 & 2 & 6 \\
\hline ÁXIMO & & 9 & 03 & 10 & 7 & 8 & ,8 & 951 \\
\hline & 4 & 3 & 1 & 1 & 1 & 2 & 2 & 5 \\
\hline ÍNIMO & & 2 & 94 & 10 & & 4 & ,3 & 198 \\
\hline & 4 & 2 & 1 & 1 & 1 & 2 & 2 & 6 \\
\hline ÉDIA & 6 & 3 & 97 & 10 & & 5 & ,5 & 058 \\
\hline
\end{tabular}


Resultados Considerando todo o Poço

\begin{tabular}{|c|c|c|c|c|c|c|c|c|}
\hline- & $D$ & $R$ & $S$ & $D$ & $v$ & $P$ & $R$ & $S$ \\
\hline & IR & $G$ & $P$ & $T$ & $S H$ & Hle & $w$ & $D T$ \\
\hline$M$ & 1 & 1 & 2 & 1 & 2 & 3 & 1 & 0 \\
\hline ÁXIMO & 00 & 376 & 36 & 10 & 5 & 1 & 6 & 951 \\
\hline & 4 & 3 & 1 & 1 & 0 & 2 & 2 & 6 \\
\hline Í́NIMO & & 0 & 90 & 10 & & 3 & , & 30 \\
\hline & 2 & 2 & 2 & 1 & 1 & 2 & 5 & 2 \\
\hline ÉDIA & 5 & 44 & 23 & 10 & 9 & 5 & ,2 & 497 \\
\hline
\end{tabular}

\section{OBSERVAC̄̃̃ES :}

DIR em Ohm.m, RG em GAPI, SP em mV, DT em microssegundos/pé, VSH (argilosidade) em \%, PHle (porosidade efetiva) em \%, Rw em Ohm.m a temperatura da profundidade e SDT em ppm. 